\title{
Synthesis of an organic-soluble $\pi$-conjugated [3]rotaxane via rotation of glucopyranose units in permethylated $\beta$-cyclodextrin
}

\author{
Jun Terao*, Yohei Konoshima, Akitoshi Matono, Hiroshi Masai, Tetsuaki Fujihara \\ and Yasushi Tsuji
}

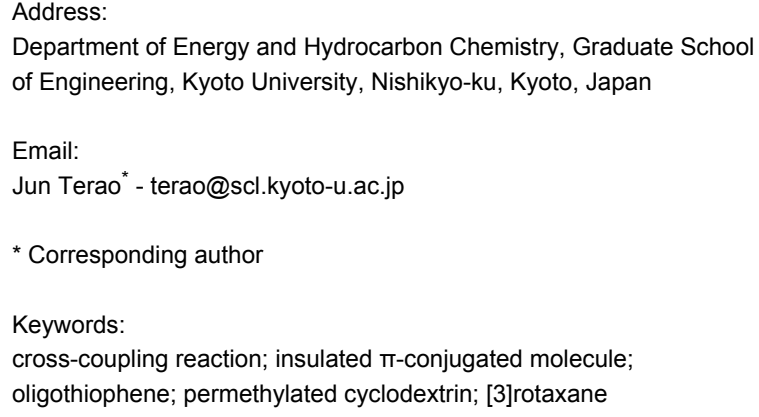

Beilstein J. Org. Chem. 2014, 10, 2800-2808. doi:10.3762/bjoc.10.297

Received: 24 June 2014

Accepted: 10 November 2014

Published: 28 November 2014

This article is part of the Thematic Series "Superstructures with cyclodextrins: Chemistry and applications II".

Guest Editor: G. Wenz

(c) 2014 Terao et al; licensee Beilstein-Institut. License and terms: see end of document.

\begin{abstract}
We synthesized symmetrically insulated oligo(para-phenylene) and oligothiophene with a pseudo-linked [3]rotaxane structure by full rotation of glucopyranose units via a flipping (tumbling) mechanism in the $\pi$-conjugated guest having two permethylated $\beta$-cyclodextrin units at both ends. We also succeeded in the synthesis of an organic-soluble fixed [3] rotaxane by a cross-coupling or complexation reaction of thus formed pseudo linked [3] rotaxane. Oligo(para-phenylene), oligothiophene, and porphyrin derivatives were used as $\pi$-conjugated guests with stopper groups.
\end{abstract}

\section{Introduction}

Insulated molecular wires (IMWs) [1,2], which feature $\pi$-conjugated polymer chains covered by protective sheaths, have attracted considerable attention as next-generation mono-molecular electronic devices because of their potential conductivity and luminescent properties [3-5]. Cyclodextrin (CD) derivatives are widely used as a protective sheath for the synthesis of IMWs because they are easily obtainable and efficient in the inclusion of various polymers into their cavity via hydrophobic interactions in water [6,7]. General methods for the synthesis of $\pi$-conjugated polymer-based IMWs using CD derivatives involve (I) threading $\pi$-conjugated polymers through $\mathrm{CD}[8,9]$ using a method developed by Harada for the synthesis of a polyrotaxane [10], (II) polymerization of pseudo [2] rotaxane monomer formed by self-inclusion of a $\pi$-conjugated guest with CD [11], and (III) copolymerization of the thus-formed pseudorotaxane with linker molecules [12]. These polymers are 
soluble in water but generally insoluble in organic solvents; this is because the hydrophilic CD covers the organic soluble $\pi$-conjugated polymer chains [13]. Uncovered sites are also randomly present because of shuttling of CDs along the $\pi$-conjugated chain and remnant water molecules; these affect the charge-transport ability and are disadvantageous for the use of these IMWs as electronic materials. Therefore, we decided to use permethylated cyclodextrin (PMCD) provided by permethylation of all the hydroxy groups of $\mathrm{CD}$. However, the low solubility of PMCD in water as compared with native CDs or other randomly methylated CDs such as 2,6-dimethyl- $\beta$-cyclodextrin impedes the formation of self-inclusion complexes via hydrophobic interactions in water. To rise above this problem, we prepared organic-soluble host-guest-linked PMCD derivatives that can undergo intramolecular self-inclusion to form an insulated molecule with an [1] rotaxane structure in methanolic aqueous solutions, where PMCD derivatives are soluble in. We recently developed a new method for synthesizing $\pi$-conjugated IMWs with polyrotaxane structures via polymerization of $\pi$-conjugated [1]rotaxane monomers bearing PMCDs as macrocycles [14]. Further, we confirmed that such IMWs with poly[1]rotaxane structure are highly soluble in a variety of organic solvents and have good rigidity, photoluminescence efficiency [15], and charge mobility [16,17]. A key step for the synthesis of these IMWs is the preparation of insulated $\pi$-conjugated monomers with [1] rotaxane structures by self-inclusion of $\pi$-conjugated monomer-linked PMCDs followed by elongation of the $\pi$-conjugated units via cross-coupling in a hydrophilic solvent, such as an aqueous 50\% methanol solution [18]. For this method, it is necessary that the molecular length of the $\pi$-conjugated guest is less than the internal diameter of the CD and similar to the depth of PMCD in order to form the selfinclusion complex (Figure 1b). When the $\pi$-conjugated guest is shorter than the depth of PMCD, the cross-coupling reaction is strongly inhibited because the reaction has to occur in the PMCD cavity (Figure 1a). On the other hand, a self-inclusion complex does not form if the guest is longer than the internal diameter of PMCD (Figure 1c). Thus far, we have succeeded in the synthesis of insulated $\pi$-conjugated monomers with [1]rotaxane structures using oligo(phenylene-ethylene) units, which have the appropriate length, as the $\pi$-conjugated guests for the fixation of self-inclusion complexes by elongation of the guest unit via cross-coupling (Figure 1b). However, this method can only be applied to the synthesis of insulated oligo(phenylene-ethylene) monomers. To synthesize other insulated $\pi$-conjugated molecules, we became interested in another insulation technique to replace this self-inclusion: full rotation of the glucopyranose units of methylated cyclodextrin by alteration of the relative orientation of the D-glucopyranoside rings via a flipping (tumbling) mechanism as shown in Figure 2 [1922]. From the results of our study on the synthesis of organic- soluble $\pi$-conjugated rotaxanes, we report herein the synthesis of insulated oligo(para-phenylene) [23] and oligothiophene [24] with linked [3]rotaxane structures via the flipping phenomenon [25].

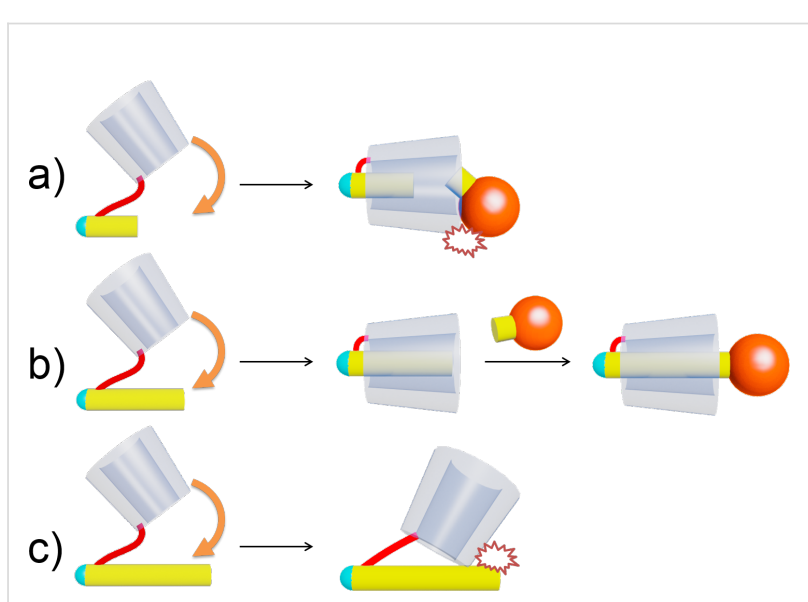

Figure 1: Synthesis of [1]rotaxane by self-inclusion of a host-guestlinked molecule: a) short molecular length, b) appropriate molecular length, c) long molecular length.

\section{Results and Discussion}

Kano and co-workers reported the synthesis of a linked pseudo [3] rotaxane involving a water-soluble porphyrin unit with carboxylate groups as the guest unit by double self-inclusion via sequential flipping of permethylated $\beta$-cyclodextrin (PM $\beta-C D)$ in water [26]. To synthesize an organic-soluble insulated $\pi$-conjugated rotaxane, we applied this technique to the synthesis of an insulated porphyrin without water-soluble functional groups. The synthetic route to the PM $\beta$-CD based linked [3]rotaxane precursor with a 5,15-di([1,1'-biphenyl]-4-yl)porphyrin backbone as the guest unit is shown in Scheme 1. In order to fix the pseudo [3] rotaxane structure, we introduced two bromo groups (cross-coupling reaction point) at both terminal positions of the 5,15-di([1,1'-biphenyl]-4-yl)porphyrin unit and two PM $\beta$-CD groups at meta position to the bromo groups. 7-O-Monotosyl PM $\beta$-CD 1 was synthesized from a native $\beta$-cyclodextrin in two steps using an established protocol [27]. Reaction of 1 with 5-bromo-2-iodophenol (2) afforded benzenelinked PM $\beta$-CD 3. The 2:1 Suzuki cross-coupling reaction of thus-formed 3 with dipinacolborane porphyrin derivative 4 gave rise to precursor of pseudo [3] rotaxane 5. It should be noted that pseudo-linked [3] rotaxane 6 formed quantitatively via double self-inclusion through flipping of 5 in an aqueous $50 \%$ methanol solution.

This unique phenomenon has been characterized by ${ }^{1} \mathrm{H}$ NMR in different solvents (Figure 3). The ${ }^{1} \mathrm{H}$ NMR spectrum in $\mathrm{CD}_{2} \mathrm{Cl}_{2}$ reveals that the 5,15-di([1,1'-biphenyl]-4-yl)porphyrin moiety is 


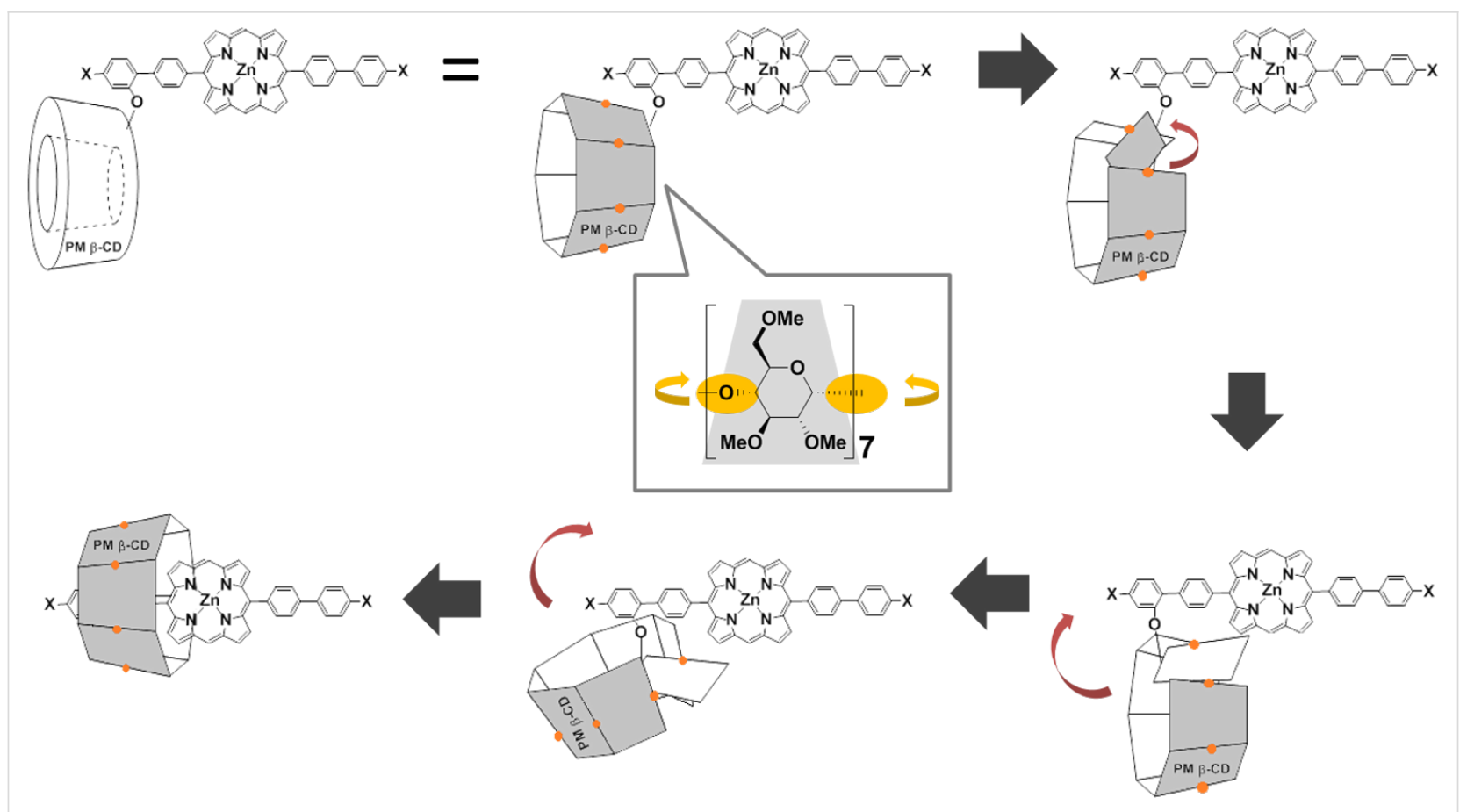

Figure 2: Synthesis of an insulated molecule via flipping phenomenon.

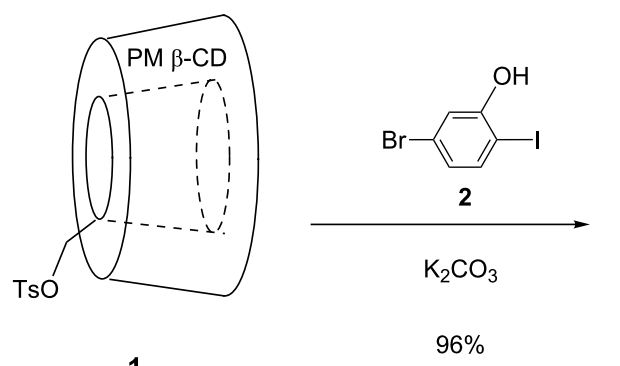

1

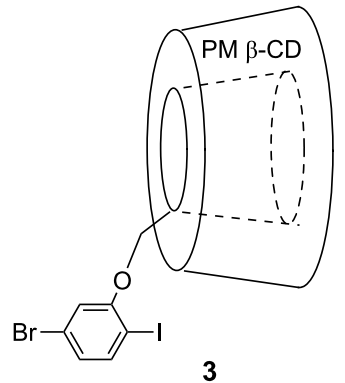

3

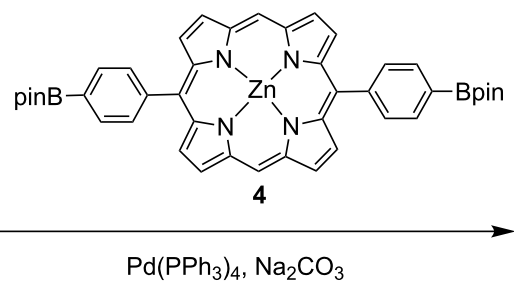

toluene/EtOH/ $\mathrm{H}_{2} \mathrm{O} 5: 1: 2$

$72 \%$

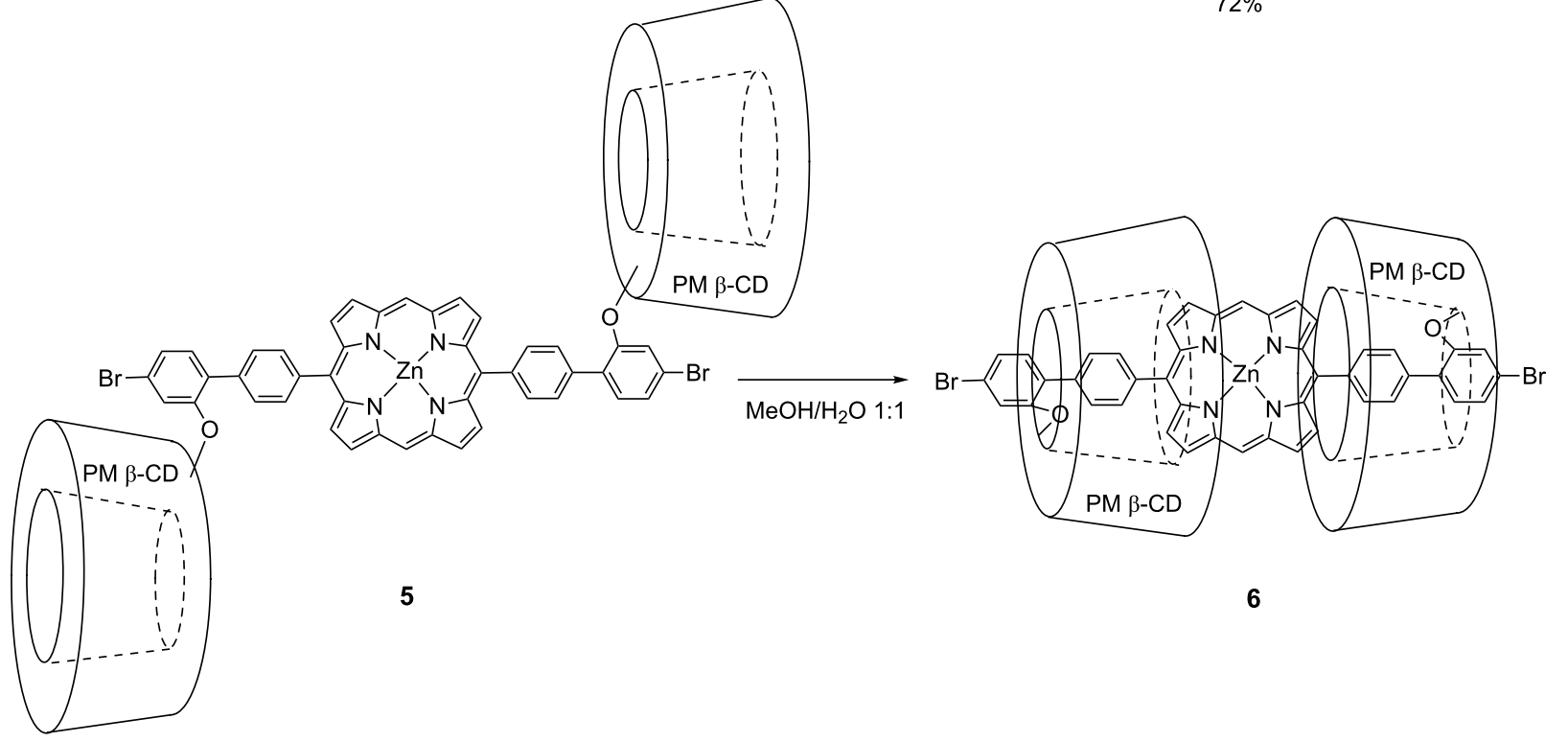

Scheme 1: The synthetic route to the PMß-CD based linked [3]rotaxane with a 5,15-di([1,1'-biphenyl]-4-yl)porphyrin backbone. 


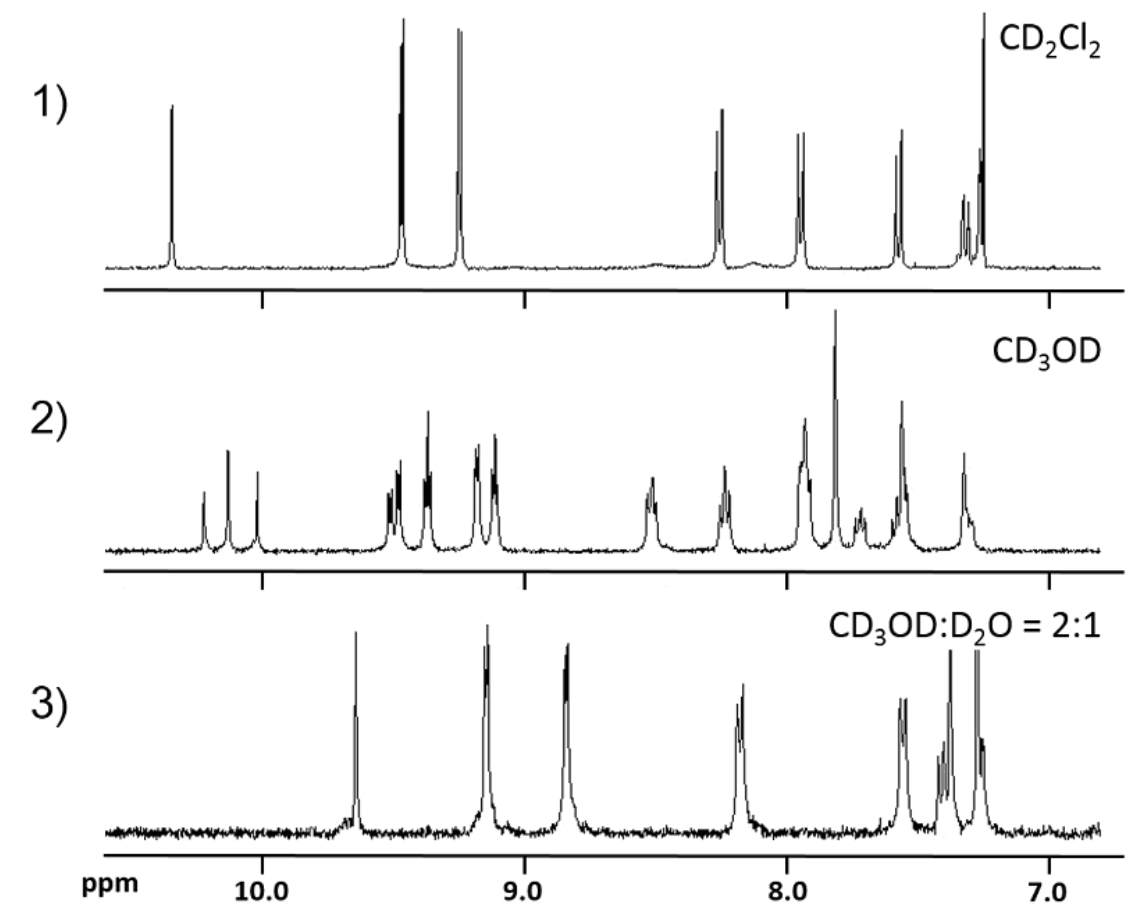

Figure 3: The aromatic region of the ${ }^{1} \mathrm{H}$ NMR spectra of 5 at $25^{\circ} \mathrm{C}:$ 1) $\mathrm{CDCl}_{3}$, 2) $\mathrm{CD}_{3} \mathrm{OD}$, and 3) $\mathrm{CD}_{3} \mathrm{OD}: \mathrm{D}_{2} \mathrm{O}$ 1:1.

excluded from the cavity of the PM $\beta-\mathrm{CD}$, while the ${ }^{1} \mathrm{H}$ NMR spectrum in $\mathrm{CD}_{3} \mathrm{OD}$ reveals a mixture of exclusion and inclusion complexes. On increasing the hydrophilicity of the solvent, the formation of double inclusion complex 6 predominated. When we added $\mathrm{D}_{2} \mathrm{O}$ in order to increase hydrophilicity, the exclusion complex completely converted into inclusion complex 6 in $\mathrm{CD}_{3} \mathrm{OD}: \mathrm{D}_{2} \mathrm{O}=1: 1$ solutions.

To synthesize an organic-soluble linked [3] rotaxane, we then fixed this pseudo rotaxane structure, which was only present in $50 \%$ methanol aqueous solution. The capping reaction by Suzuki cross-coupling with pinacolboron derivative 7 bearing PM $\alpha$-CD as the bulky stopper group was carried out under the same hydrophilic solvent conditions as in the formation of $\mathbf{6}$ (Scheme 2). The desired fixed [3] rotaxane 9 was isolated in $31 \%$ yield by preparative size exclusion chromatography using $\mathrm{CHCl}_{3}$ as the eluent. The corresponding uninsulated compound 8 as a reference was also intentionally synthesized by the reaction of 5 with 7 in hydrophobic solvent (toluene/ $\mathrm{H}_{2} \mathrm{O}$ 5:1) instead of hydrophilic solvent $\left(\mathrm{CH}_{3} \mathrm{OH} / \mathrm{H}_{2} \mathrm{O}\right.$ 1:1). Although the MALDI-TOF mass spectrum of $\mathbf{8}$ and $\mathbf{9}$ exhibited the same signal at $m / z=6097$ corresponding to $[\mathbf{8} \text { or } \mathbf{9}+\mathrm{Na}]^{+}$, each ${ }^{1} \mathrm{H}$ NMR spectrum of those showed the pure single product but completely different, respectively. These results suggest that we succeeded in the selective synthesis of $\mathbf{8}$ and $\mathbf{9}$ by simply changing the reaction solvent.
We next applied this synthetic method to other $\pi$-conjugated guests. Scheme 3 shows the synthetic routes to precursor of PM $\beta$-CD based insulated oligothiophene. Mono-6-desmethyl PM $\beta-C D$ alcohol 10 was synthesized from 1 using sodium naphthalenide [27]. The reaction of the thus-formed monoalcohol with 2-bromo-3-(bromomethyl)thiophene (11) afforded thiophene-linked PM $\beta$-CD 12. Pd-catalyzed Stille cross-coupling of 12 with bithiophene $\mathbf{1 3}$ bearing a silylprotected alkynyl group afforded trithiophene-linked PM $\beta$-CD 14. After the deprotection of the triisopropyl group of $\mathbf{1 4}$ and the Glaser dimerization reaction of $\mathbf{1 5}$, symmetrical oligothiophene 16 bearing two PM $\beta$-CDs was obtained. Treatment of 16 with $\mathrm{Na}_{2} \mathrm{~S}$ and $\mathrm{KOH}$ followed by dibromination by $\mathrm{N}$-bromosuccinimide formed dibromo-heptathiophene 17 with two PMCDs.

Scheme 4 shows the synthetic route to the precursor of PM $\beta$-CD-based insulated oligo(para-phenylene) 20. Sequential Suzuki cross-coupling of $\mathbf{3}$ with unsymmetrically protected benzene-1,4-diboronic acid derivative $\mathbf{1 8}$ and diiodobiphenyl gave rise to hexa(para-phenylene) derivative $\mathbf{2 0}$.

Pseudo linked [3] rotaxanes $\mathbf{2 1}$ and $\mathbf{2 2}$ were also formed quantitatively in an aqueous $50 \%$ methanol solution via double self-inclusion through flipping of $\mathbf{1 7}$ and 20, respectively (Scheme 5). The formation of these inclusion complexes 


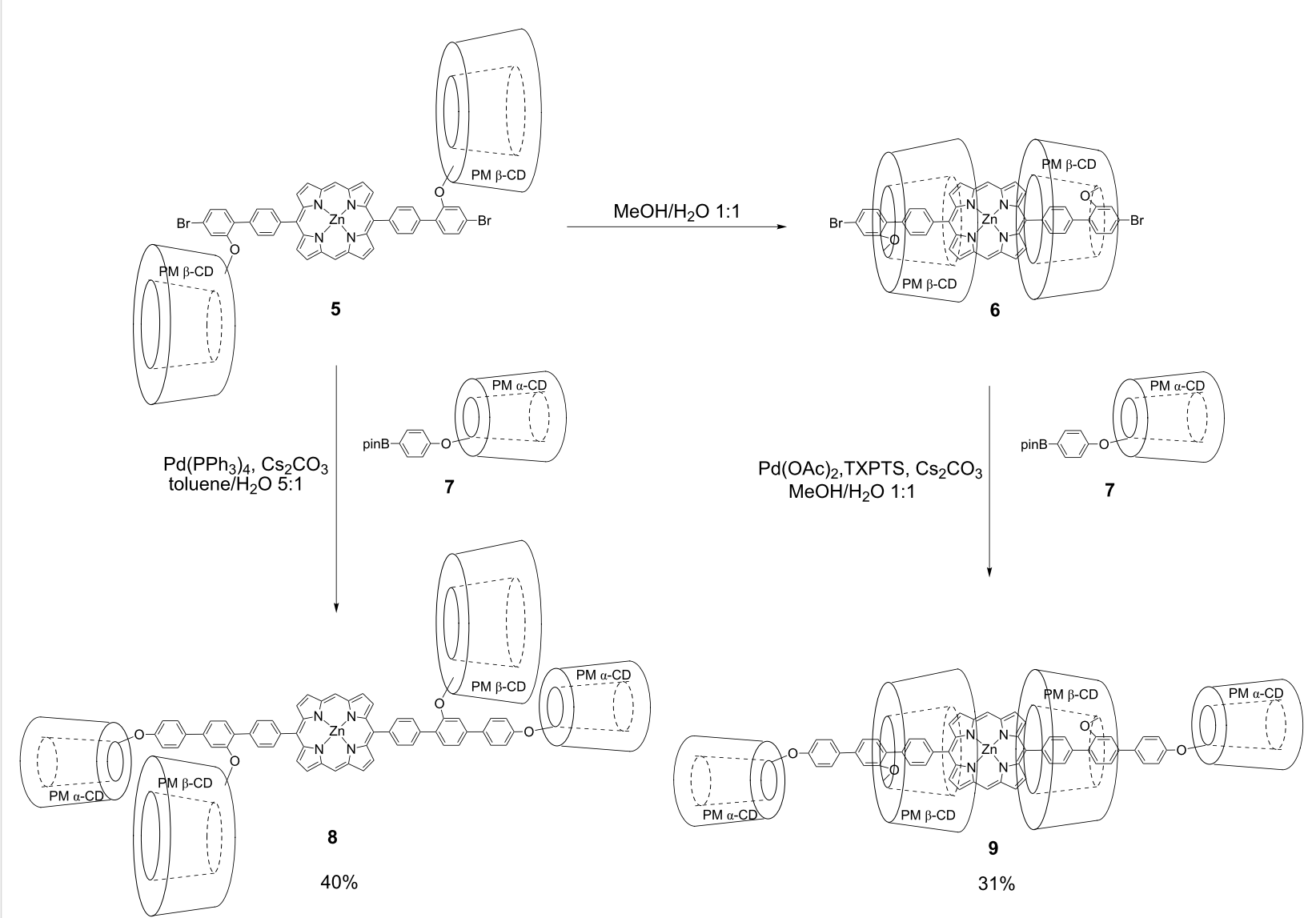

Scheme 2: Selective synthesis of fixed [3]rotaxane by Suzuki cross-coupling reaction.

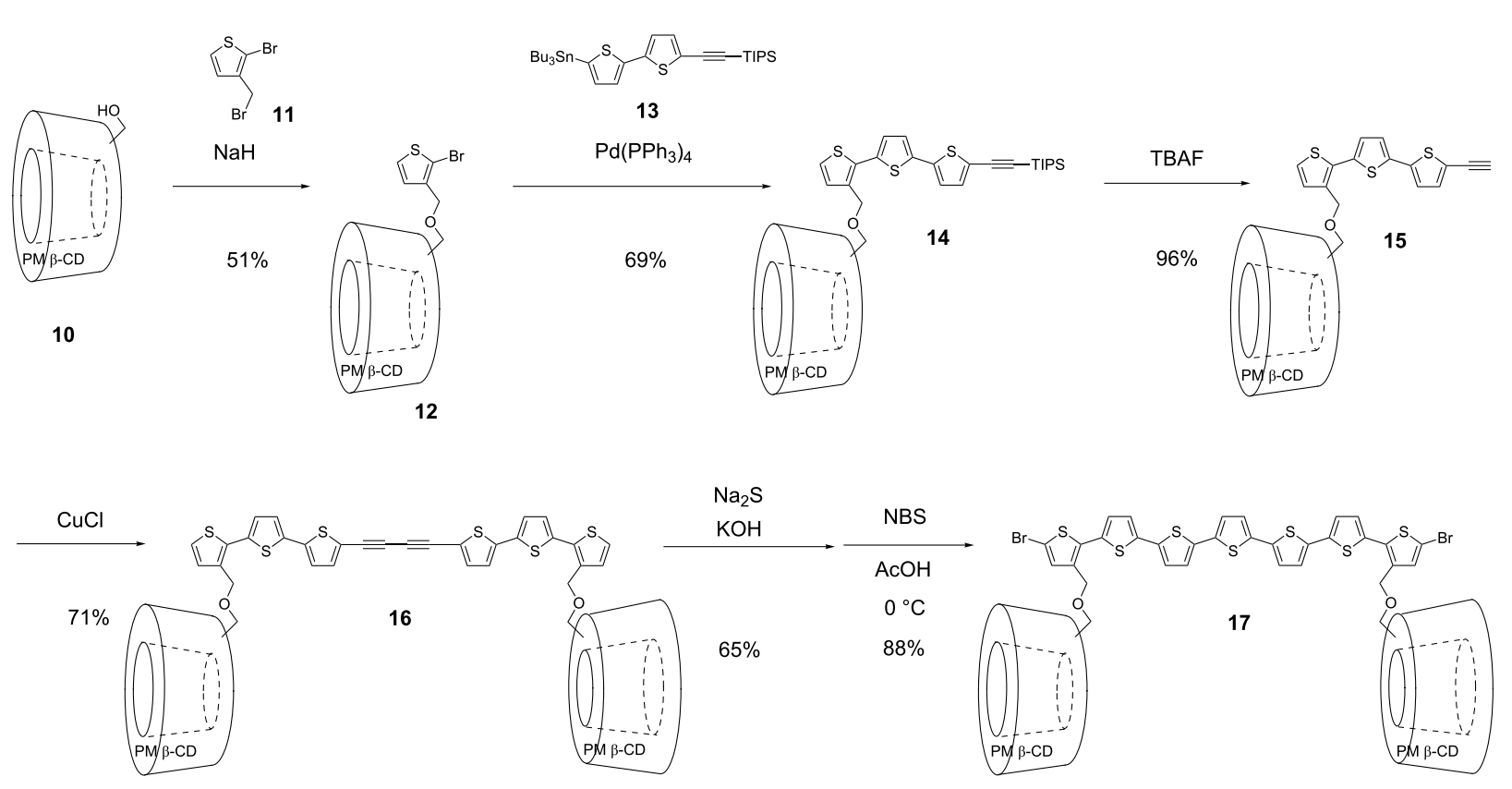

Scheme 3: The synthetic routes to precursor of $P M \beta-C D$ based insulated oligothiophene. 


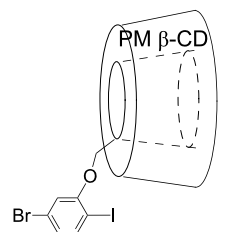

3

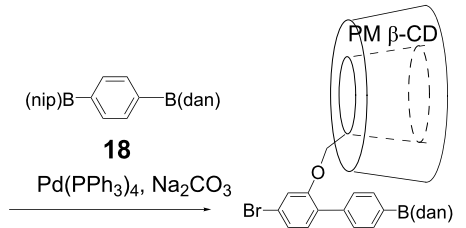

$87 \%$

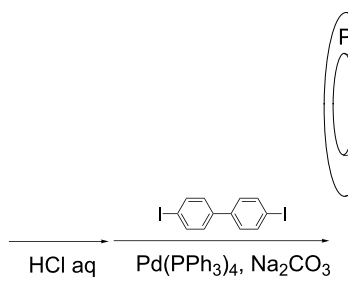

$62 \%$
20

Scheme 4: Synthesis of dibromohexa(para-phenylene) with two PMCDs 20.

were also confirmed by ${ }^{1} \mathrm{H}$ NMR spectroscopy in different solvents (Figure 4 and Figure 5, Supporting Information File 1, Figure S2). These linked [3] rotaxanes can be key monomers for synthesizing organic soluble IMWs bearing polythiophene or poly(para-phenylene) as backbone units.

We next fixed the pseudo rotaxane structure by complexation instead of cross-coupling reaction (Scheme 6). First, we introduced pyridyl groups at the terminal positions of hexa(para-phenylene) precursor 20 by Suzuki cross-coupling with para-pyridylboronic acid to generate 23. After confirmation of the formation of pseudo [3] rotaxane 24 via flipping of 23 in $\mathrm{CD}_{3} \mathrm{OD} / \mathrm{D}_{2} \mathrm{O}$ 1:2 solution by ${ }^{1} \mathrm{H}$ NMR analysis, we capped this pseudo [3] rotaxane structure by reacting $\mathbf{2 4}$ with rhodium porphyrin complex $\mathbf{2 5}$ in chloroform to form fixed [3] rotaxane $\mathbf{2 6}$ in $17 \%$ isolated yield [28]. The structure of $\mathbf{2 6}$ was confirmed by ${ }^{1} \mathrm{H}$ NMR analyses in $\mathrm{CDCl}_{3}$. The results suggest that $\mathbf{2 6}$ maintains a [3] rotaxane structure even in organic solvents because it is capped with sterically bulky porphyrin units, which impede the reverse flipping of the PM $\beta-C D$ units.

As shown in Figure 6, the unique fixed [3] rotaxane structure of 26 was confirmed by $2 \mathrm{D}{ }^{1} \mathrm{H}$ ROESY NMR analysis: there are obvious nuclear Overhauser enhancements (NOEs) between the protons on the hexa(para-phenylene) unit and the $\mathrm{H} 3$ and $\mathrm{H} 5$ protons on the interior of the permethylated cyclodextrin [29]. These experimental results indicated that the rotaxane structure was constructed between PM $\beta$-CDs and para-phenylene as hosts and guest, respectively.

\section{Conclusion}

We developed the synthesis of symmetrically insulated $\pi$-conjugated molecules with pseudo linked [3] rotaxane structure via

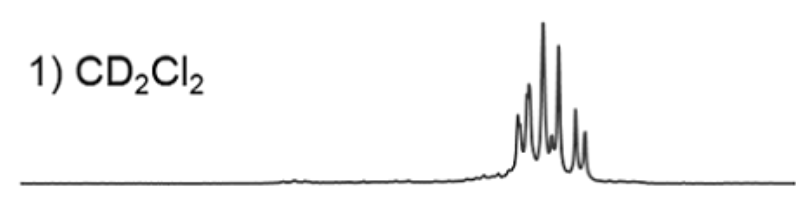

2) $\mathrm{CD}_{3} \mathrm{OD}$

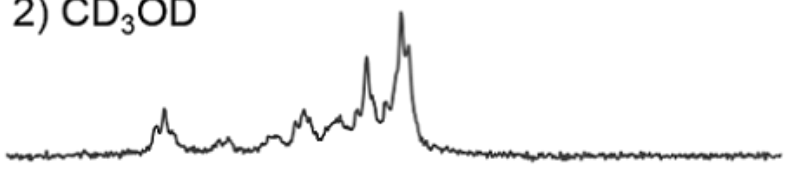

3) $\mathrm{CD}_{3} \mathrm{OD} / \mathrm{D}_{2} \mathrm{O}=1 / 1$

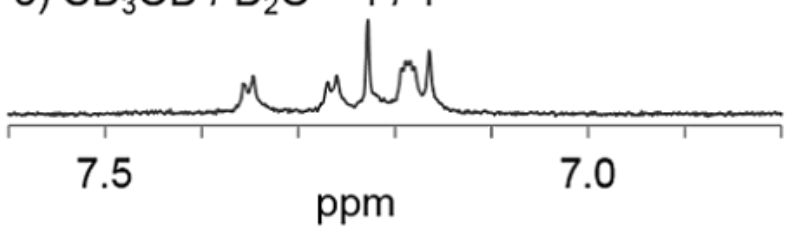

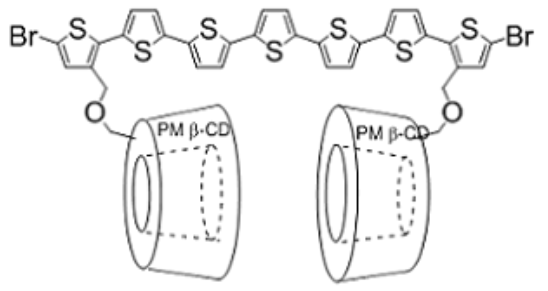

17

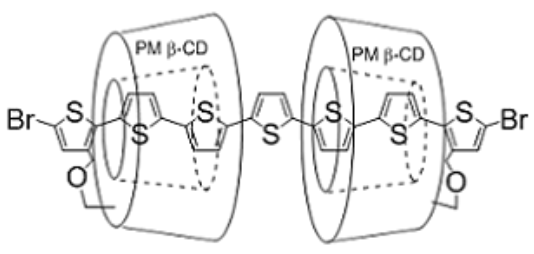

21

Figure 4: The aromatic region of the ${ }^{1} \mathrm{H}$ NMR spectra of 5 at $\left.\left.25^{\circ} \mathrm{C}: 1\right) \mathrm{CDCl}_{3}, 2\right) \mathrm{CD}_{3} \mathrm{OD}$, and $\mathrm{CD}_{3} \mathrm{OD} / \mathrm{D}_{2} \mathrm{O}$ 1:1. 

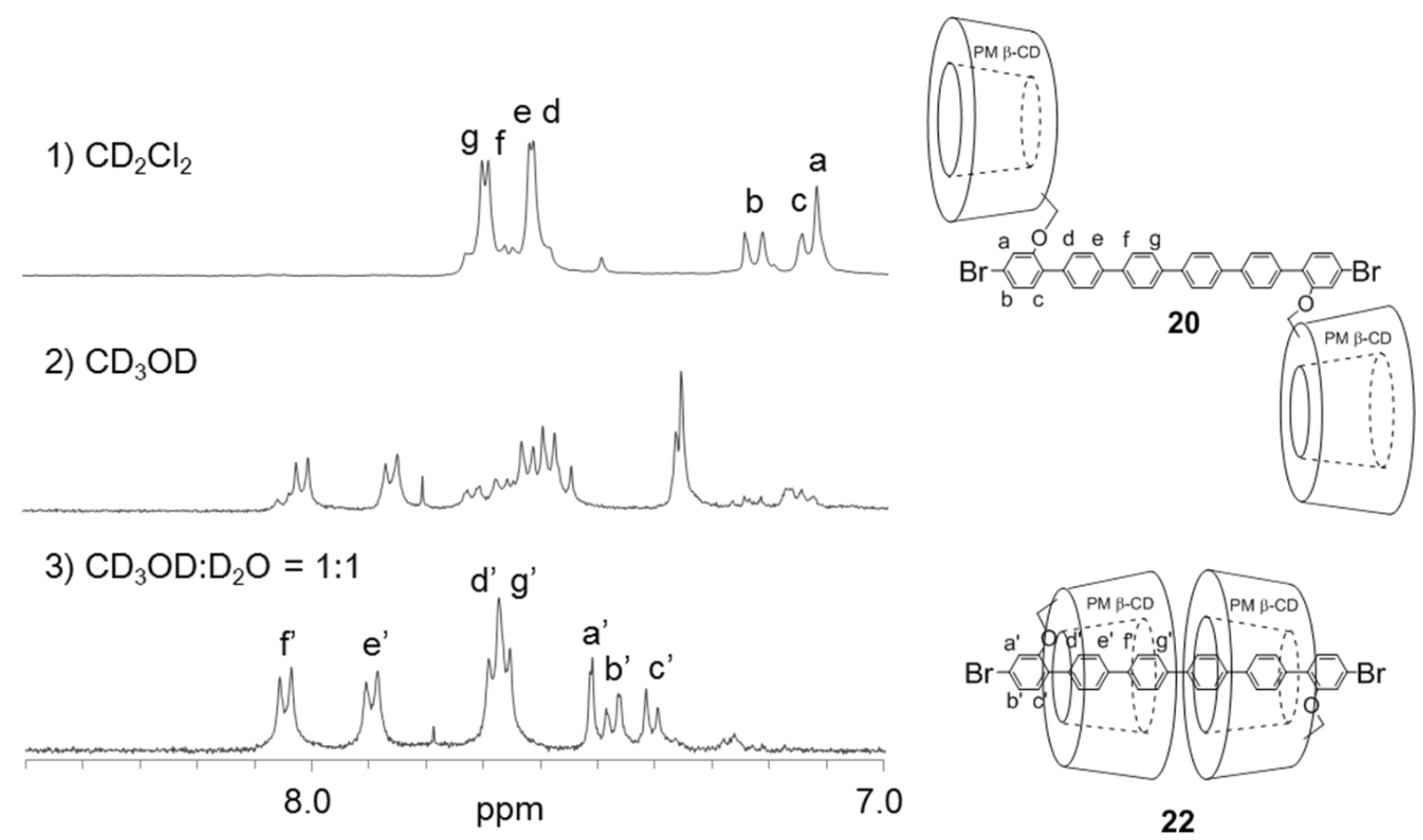

22

Figure 5: The aromatic region of the ${ }^{1} \mathrm{H}$ NMR spectra of 20 at $\left.\left.25^{\circ} \mathrm{C}: 1\right) \mathrm{CDCl}_{3}, 2\right) \mathrm{CD}_{3} \mathrm{OD}$, and $\mathrm{CD}_{3} \mathrm{OD} / \mathrm{D}_{2} \mathrm{O}$ 1:1.
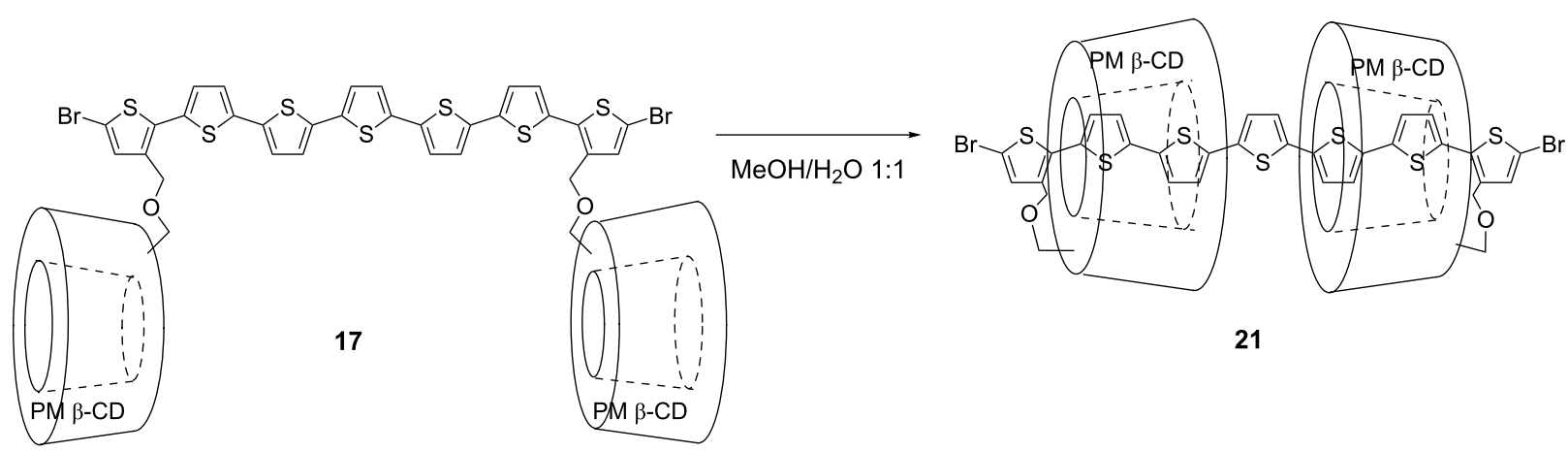

21
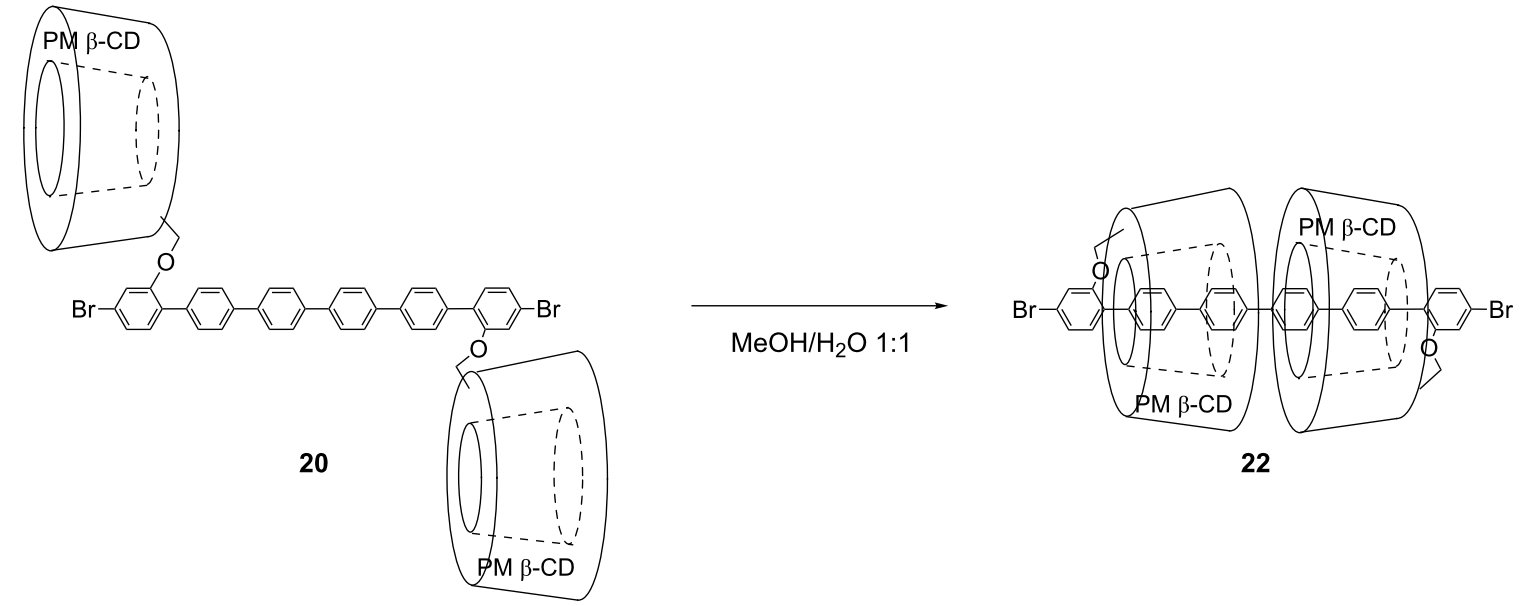

Scheme 5: Synthesis of pseudo-linked [3]rotaxanes via double self-inclusion through flipping. 


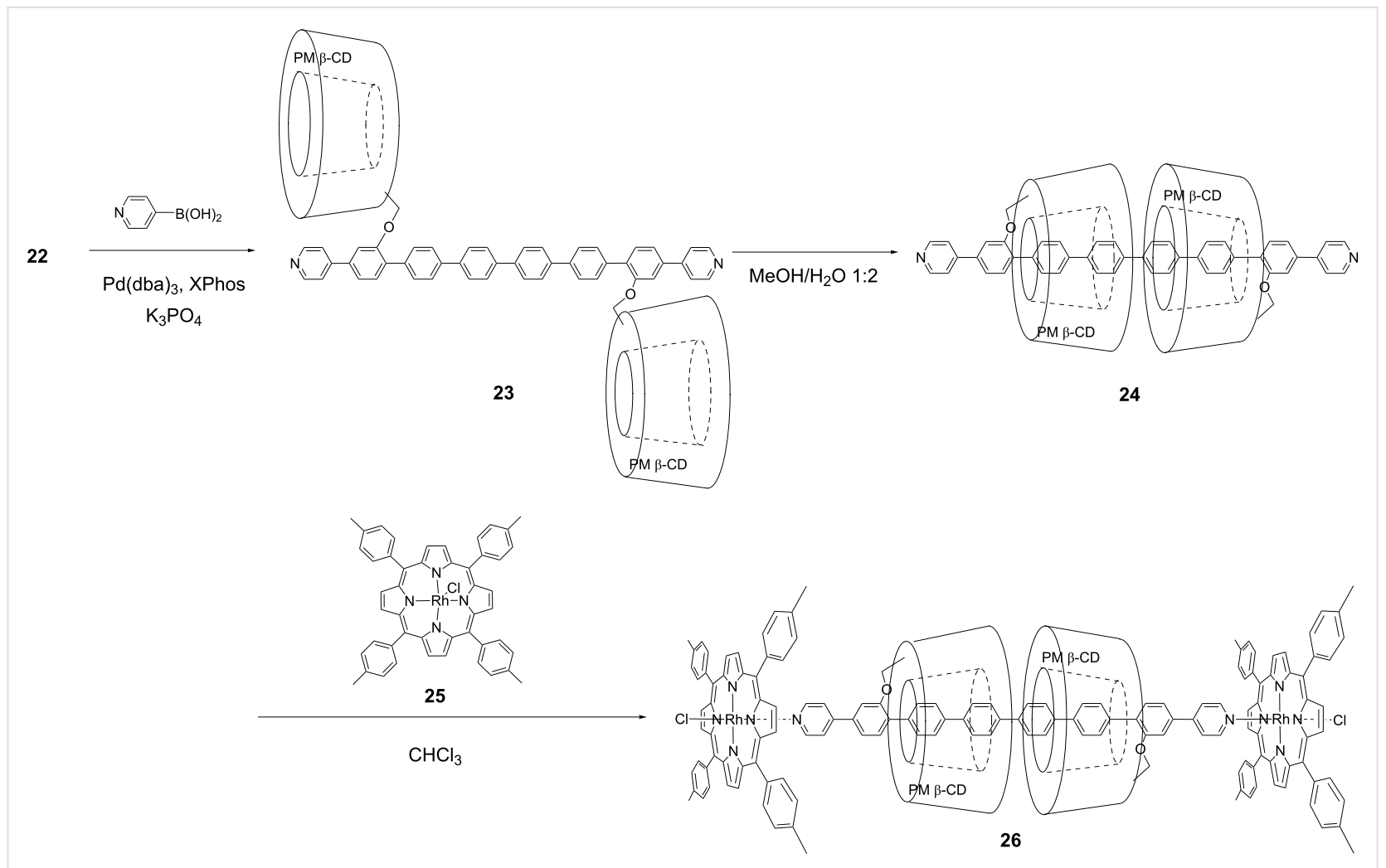

Scheme 6: Synthesis of fixed [3]rotaxane via complexation with rhodium porphyrin.

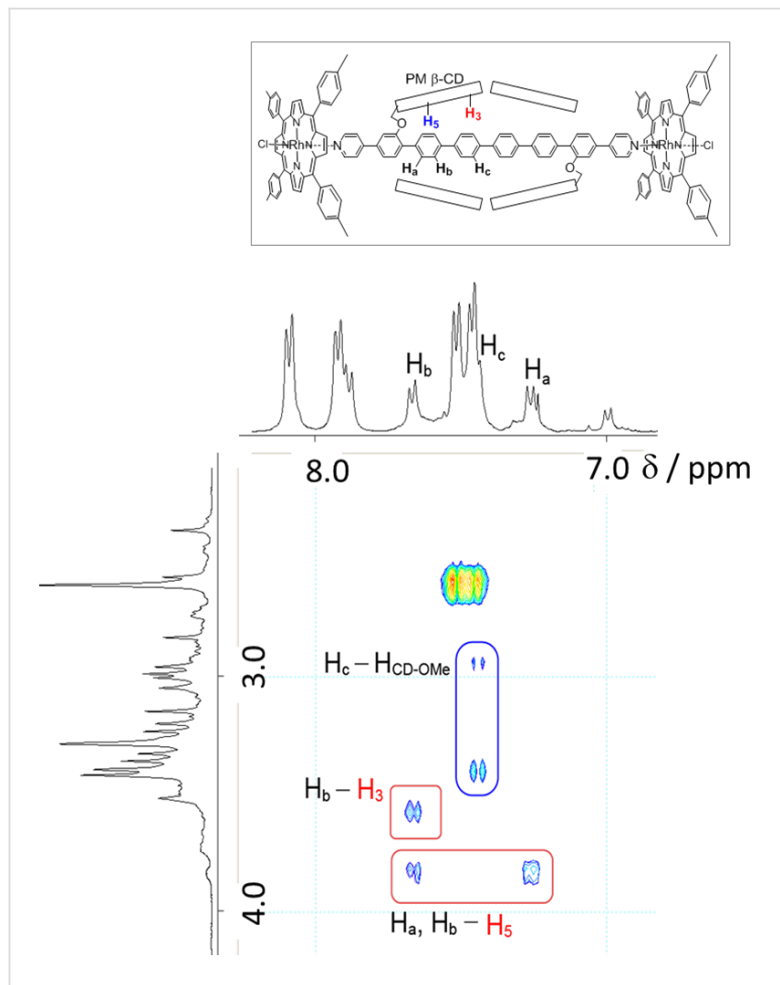

Figure 6: Partial ROESY NMR spectrum of $26\left(400 \mathrm{MHz}, \mathrm{CDCl}_{3}\right)$ showing the NOEs between aromatic protons of the axial hexa(paraphenylene) and inner protons of cyclodextrins. flipping of a glucopyranose unit of permethylated $\beta$-cyclodextrin. In this method, oligo(para-phenylene), oligothiophene, and porphyrin derivatives were used as $\pi$-conjugated guests. After cross-coupling or complexation of the pseudo linked [3]rotaxane with capping molecules, the fixed [3]rotaxane was isolated in chloroform solution. The formation of the fixed [3] rotaxane was confirmed by NMR analysis. Experiments are now in progress towards synthesizing IMWs bearing polythiophene or poly(para-phenylene) as backbone units by polymerization of these linked [3] rotaxanes as monomers.

\section{Supporting Information}

\section{Supporting Information File 1}

Experimental and analytical data.

[http://www.beilstein-journals.org/bjoc/content/

supplementary/1860-5397-10-297-S1.pdf]

\section{Acknowledgements}

This research was supported by the Funding Program for JSPS Research Fellow, Next Generation World-Leading Researchers, and Grant-in-Aid for Scientific Research on Innovative Areas ("Molecular Architectonics" and "Soft Molecular Systems") from MEXT, Japan. 


\section{References}

1. Wenz, G. Inclusion Polymers; Springer Verlag, 2009. doi:10.1007/978-3-642-01410-9

2. Frampton, M. J.; Anderson, H. L. Angew. Chem., Int. Ed. 2007, 46, 1028-1064. doi:10.1002/anie.200601780

3. Petty, M. C. In Molecular Electronics from Principles to Practice, John Wiley \& Sons: Chippenham 2007.

4. Jalabert, A.; Amara, A.; Clermidy, F. In Molecular Electronics Materials, Devices and Applications, Springer: New York 2008.

5. Taniguchi, M.; Nojima, Y.; Yokota, K.; Terao, J.; Sato, K.; Kambe, N.; Kawai, T. J. Am. Chem. Soc. 2006, 128, 15062-15063. doi:10.1021/ja065806z

6. Wenz, G.; Han, B.-H.; Müller, A. Chem. Rev. 2006, 106, 782-817. doi:10.1021/cr970027+

7. Harada, A.; Takashima, Y.; Yamaguchi, H. Chem. Soc. Rev. 2009, 38, 875-882. doi:10.1039/b705458k

8. Yoshida, K.-i.; Shimomura, T.; Ito, K.; Hayakawa, R. Langmuir 1999, 15, 910-913. doi:10.1021/la9812471

9. Yamaguchi, I.; Kashiwagi, K.; Yamamoto, T. Macromol. Rapid Commun. 2004, 25, 1163-1166. doi:10.1002/marc.200400024

10. Harada, A.; Li, J.; Kamachi, M. Nature 1992, 356, 325-327. doi:10.1038/356325a0

11. Shinohara, K.-i.; Suzuki, T.; Kitami, T.; Yamaguchi, S. J. Polym. Sci., Part A: Polym. Chem. 2006, 44, 801-809. doi:10.1002/pola.21175

12. Michels, J. J.; O'Connell, M. J.; Taylor, P. N.; Wilson, J. S.; Cacialli, F.; Anderson, H. L. Chem. - Eur. J. 2003, 9, 6167-6176. doi:10.1002/chem.200305245

13. Frampton, M. J.; Sforazzini, G.; Brovelli, S.; Latini, G.; Townsend, E.; Williams, C. C.; Charas, A.; Zalewski, L.; Kaka, N. S.; Sirish, M.; Parrott, L. J.; Wilson, J. S.; Cacialli, F.; Anderson, H. L. Adv. Funct. Mater. 2008, 18, 3367-3376.

14. Terao, J. Polym. Chem. 2011, 2, 2444-2452. doi:10.1039/c1py00243k

15. Terao, J.; Tsuda, S.; Tanaka, Y.; Okoshi, K.; Fujihara, T.; Tsuji, Y.; Kambe, N. J. Am. Chem. Soc. 2009, 131, 16004-16005. doi:10.1021/ja9074437

16. Terao, J.; Tanaka, Y.; Tsuda, S.; Kambe, N.; Taniguchi, M.; Kawai, T.; Saeki, A.; Seki, S. J. Am. Chem. Soc. 2009, 131, 18046-18047. doi:10.1021/ja908783f

17. Terao, J.; Wadahama, A.; Matono, A.; Tada, T.; Watanabe, S.; Seki, S.; Fujihara, T.; Tsuji, Y. Nat. Commun. 2013, 4, 1691. doi:10.1038/ncomms2707

18. Terao, J. Chem. Rec. 2011, 11, 269-285. doi:10.1002/tcr.201100009

19. Jullien, L.; Canceill, J.; Lacombe, L.; Lehn, J.-M. J. Chem. Soc., Perkin Trans. 2 1994, 989-1002. doi:10.1039/p29940000989

20. Yamada, T.; Fukuhara, G.; Kaneda, T. Chem. Lett. 2003, 534-535. doi:10.1246/cl.2003.534

21. Yamauchi, K.; Miyawaki, A.; Takashima, Y.; Yamaguchi, H.; Harada, A. Org. Lett. 2010, 12, 1284-1286. doi:10.1021/ol1001736

22. Liu, Y.; Chipot, C.; Shao, X.; Cai, W. J. Phys. Chem. C 2014, 118, 19380-19386. doi:10.1021/jp503866q

23. Taylor, P. N.; O'Connell, M. J.; McNeill, L. A.; Hall, M. J.; Aplin, R. T.; Anderson, H. L. Angew. Chem., Int. Ed. 2000, 39, 3456-3460.

24. Sakamoto, K.; Takashima, Y.; Yamaguchi, H.; Harada, A. J. Org. Chem. 2007, 72, 459-465.

25. Yerin, A.; Wilks, E. S.; Moss, G. P.; Harada, A. Pure Appl. Chem. 2008, 80, 2041-2068.
26. Nishiyabu, R.; Kano, K. Eur. J. Org. Chem. 2004, 24, 4985-4988. doi:10.1002/ejoc.200400309

27. Kaneda, T.; Fujimoto, T.; Goto, J.; Asano, K.; Yasufuku, Y.; Jung, J. H.; Hosono, C.; Sakata, Y. Chem. Lett. 2002, 31, 514-515. doi:10.1246/cl.2002.514

28. Masai, H.; Terao, J.; Seki, S.; Nakashima, S.; Kiguchi, M.; Okoshi, K.; Fujihara, T.; Tsuji, Y. J. Am. Chem. Soc. 2014, 136, 1742-1745. doi:10.1021/ja411665k

29. Fujimoto, T.; Sakata, Y.; Kaneda, T. Chem. Commun. 2000, 2143-2145. doi:10.1039/b006758j

\section{License and Terms}

This is an Open Access article under the terms of the Creative Commons Attribution License

(http://creativecommons.org/licenses/by/2.0), which permits unrestricted use, distribution, and reproduction in any medium, provided the original work is properly cited.

The license is subject to the Beilstein Journal of Organic Chemistry terms and conditions: (http://www.beilstein-journals.org/bjoc)

The definitive version of this article is the electronic one which can be found at: doi:10.3762/bjoc. 10.297 